6 - ORIGINAL ARTICLE

WOUND HEALING

\title{
Effects of chitin and sepia ink hybrid sponge on the healing of burning wound rats and its impact on macrophages in vitro ${ }^{1}$
}

\author{
Wei ZhangI, Yan Wang ${ }^{\mathrm{II}}$, Xianxian Sui' ${ }^{\mathrm{III}}$, Yulin Sun ${ }^{\mathrm{IV}}$, Daohai Chen ${ }^{\mathrm{V}}$ \\ DOI: http://dx.doi.org/10.1590/S0102-865020160020000006
}

IFellow Master degree, Postgraduate Program in Biomedcial Materimals, Lingnan Normal University, Round Beibu Gulf Institute for the Protection and Utilization of Marine Animals in Medicine (RBGPUM), China. Conception, design, intellectual and scientific content of the study; acquisition and interpretation of data; manuscript writing.

IFellow Master degree, Postgraduate Program in Surgery, Life Science and Technology School, Lingnan Normal University, China. Acquisition and interpretation of data, design of the study, technical procedures.

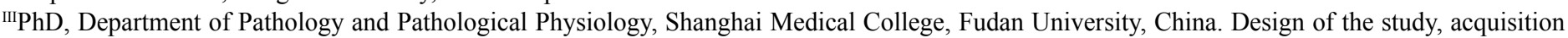
and interpretation of data technical procedures.

${ }^{\mathrm{IV}} \mathrm{PhD}$, Postgraduate Program in Natural Medicine, Life Science and Technology School, Lingnan Normal University, China. Critical revision.

${ }^{v}$ Full Professor, Postgraduate Program in Medicinal Animals, Lingnan Normal University, RBGPUM, China. Conception, design, intellectual and scientific content of the study.

\section{ABSTRACT}

PURPOSE: To detect whether chitin and sepia ink sponge (CS) can promote wound healing and elevate impact of CS on phagocytosis ability of macrophages.

METHODS: Forty-eight rats were assigned to four groups: Normal group (Normal), negative control group (Con), chitin and sepia ink sponge group (CS) and positive control Surgicel Gauze ${ }^{\circledR}$ group (SG). Deep second-degree burn model was created in rats. Wound area was recorded by digital imaging and determined using Image $\mathrm{J}$ software. Samples were collected and kept at $-80^{\circ} \mathrm{C}$ on $3 \mathrm{~d}, 7 \mathrm{~d}, 14 \mathrm{~d}$ and $21 \mathrm{~d}$ for cytokines detecting. Transforming growth factor (TGF)- $\beta_{1}$, interleukin (IL)-6, matrix metalloproteinase (MMP)-1, hydroxyproline (Hyp) and macrophage activity reflected by tumor necrosis factor (TNF)- $\alpha$ were determined by enzyme-linked immunosorbent assay (ELISA).

RESULTS: Comparing to Con and SG, scabs in CS group fell off and basically healed on 21 day. TGF- $\beta_{1}$, IL-6, MMP-1 and Hyp were significantly increased by CS and SG comparing to Con $(\mathrm{p}<0.05)$, CS had more apparently adjustment on TGF- $\beta_{1}$ and MMP-1 compared to SG; results in vitro indicated CS significantly promoted phagocytosis ability of macrophages reflected in TNF- $\alpha(\mathrm{p}<0.05)$.

CONCLUSION: CS improved wound healing through exerting significant influences on secretion of kinds of cytokines and activating macrophages.

Key words: Chitin. Sepia. Cytokines. Macrophages. Rats. 


\section{Introduction}

Wound dressing is one of the most promising medical applications for chitin. The adhesive nature of chitin, together with the antifungal and bactericidal properties, and the permeability to oxygen, is a very important property associated with the treatment of wounds and burns ${ }^{1}$. Some studies have showed chitinbased dressing can improve repair of different tissues facilitate contraction of wounds, and regulate secretion of inflammatory mediators, such as interleukin8, prostaglandin $\mathrm{E}$, interleukin $1 \beta$ and others ${ }^{2}$. It has also been reported that chitin or its derivatives can activate macrophage to express a number of pro-inflammatory cytokines, chemokine and other mediators, by which modulate the wound healing process ${ }^{3}$.

Sepia ink contains higher trace elements of vanadium, iron, cobalt, nickel, copper, silver, cadmium, lead, and bismuth, especially calcium and strontium. It has been confirmed that trace elements are essential nutrients for tissue repair, immune, digestive function and other aspects of the role ${ }^{4}$. Researchers have founded that sepia ink has anti-radiation activity, antitumor activity, immunomodulatory activity, procoagulant function, etc $^{5}$. Chen et al. ${ }^{6}$ reported that sepia ink can raise the leukocyte content of blood, by which can promote the phagocytic activity of macrophages.

Currently, kinds of healing agents and sponge have existed, such as gelatin hydrogel, microcrystalline collagen and collagen sponges, gelatin sponge, cyanoacrylate adhesives, fibringlue and chitosan sponge ${ }^{7}$. But they basically have certain disadvatages. Collagen, fibrinogen or thrombin are expensive and include potential risk of viral infections, because they are mainly derived from animal or human blood. The adhesive properties of collagen and gelatin sponges to tissues are poor, and chitosan sponge is easy to become fragmented and dissolved away in vivo and in vitro. Water-soluble collagen has some toxicity, which may cause inflammatory responses in human body ${ }^{8}$. So, it makes sense to study a novel and safe biological agent for clinical use with better healing properties, adhesion and less tissue response. In previous work, our laboratory had prepared chitin and sepia ink sponge (CS sponge) and it exhibited good biological properities ${ }^{9}$. Compared to most other biomaterials, CS sponge is a pure biological product, which only contains chitin and sepia. During the wound healing process, CS sponge can effectively absorb the exudates slowly and can well maintain its basic sponge shape. It would adhere to the wound surface and provide a moist microenvironment for wound healing, so the wound bed would be well prevented the friction from outside, like clothing 9 .
In this paper, a deep second degree burn model of rat was used to evaluate the wound healing effects of CS sponge in vivo and also determined its impact on macrophages in vitro, from which this experiment tried to reveal its basic healing mechanism.

\section{Methods}

This project was reviewed and approved by the committee of experimental animals of Lingnan Normal University and conformed to National Institutes of Health guidelines. All experimental procedures complied with the Guide for the Care and Use of Laboratory Animals, which were made to minimize suffering of animals.

Forty-eight adults male Wistar rats $(180 \pm 20 \mathrm{~g}$, Jinan, China) were housed for one week in a room with controlled temperature at $25 \pm 1^{\circ} \mathrm{C}$ and fed with standard laboratory diet, water and light/dark cycle of 12 hours.

\section{Surgical procedures and groups formation}

All animals were anesthetized with an intra-peritoneal injection of sodium pentobarbital $(50 \mathrm{mg} / \mathrm{kg})$ and then shaved to expose skin area by an electric razor. Deep second degree burn model was mainly prepared according to literature 10. Briefly, a $2.5 \mathrm{~cm}$ in diameter steel rod (24 cm in length) was heated to $100^{\circ} \mathrm{C}$ in boiling water for $15 \mathrm{~min}$, then it was applied for $7 \mathrm{~s}$ on the removed dorsal skin of the rats and created deep second degree burn injury. The rats were randomly divided into four groups ( $\mathrm{n}$ $=12$ per group): Normal group (Normal), negative control group (Con), chitin and sepia ink sponge group (CS) and positive control Surgicel Gauze ${ }^{\circledR}$ group (SG). But Normal group did not been treated for second degree burn, which was only taken blood for cytokine analysis at each time point; chitin and sepia ink sponge group was covered by $3 \mathrm{~cm} \times 3 \mathrm{~cm}$ chitin and sepia ink sponge; positive control Surgicel Gauze ${ }^{\circledR}$ group was covered by $3 \mathrm{~cm} \times 3$ cm Surgicel Gauze ${ }^{\circledR}$; negative control group did not be treated after disinfected. Finally, to prevent wound infecitons from external factors, Hainuo ${ }^{\circledR}$ (Qingdao, China) adhesive wound dressing was applied to cover up the burn area of each rat. Seven days later, no sterile wound dressing was applied for conveniently checking the healing process.

The gross finding of healing process was recorded using the Image $J$ software (National Institutes of Health, USA) every three days. The rats were sacrificed on 3, 7, 14 and 21 days, and the burn sites including the surround tissues were harvested. Samples were immediately frozen in liquid nitrogen after harvest and stored at $-80{ }^{\circ} \mathrm{C}$ for ELISA determining. 


\section{Observation of wound healing}

The appearance of the wound was recorded by digital imaging at 1, 3, 7, 14 and 21 days. Wound areas was determined from the digital images using Image $\mathrm{J}$ software (National Institutes of Health, USA).

\section{Assay of TGF- $\beta_{1}, I L-6$ and MMP-1 in the wounded skin}

On the test day, frozen samples were weighed and allowed to thaw in ice-cold lysis buffer (Beyotime, China) at the ration of $100 \mathrm{mg} / \mathrm{mL}$. The buffer contained $20 \mathrm{mmol} / \mathrm{L}$ Tris $(\mathrm{PH}$ 7.5), $150 \mathrm{mmol} / \mathrm{L} \mathrm{NaCl}, 1 \%$ Triton X-100, $\beta$-glycerophosphate, sodium pyrophosphate, EDTA, $\mathrm{Na}_{3} \mathrm{VO}_{4}$, leupeptin and 1 mM PMSF (Phenylmethanesulfonyl fluoride). Samples were homogenized with a tissue homogenizer (IKA, Germany). The homogenized were centrifuged at $4^{\circ} \mathrm{C}$ for $20 \mathrm{~min}(10000 \mathrm{r} / \mathrm{min})$ before the supernatants obtained. The content of TGF- $\beta_{1}$, IL- 6 and MMP-1 were examined by ELISA Kits (R\&D Systems, USA) and normalized by total protein content of each sample. Protocols for all of these assays were followed as indicated by the manufacturer and all assays were performed in duplicate.

\section{Detection of hydroxyproline in the wound area}

The Hyp content was determined through digestion method by ELISA (Nanjing, China). 10\% tissue samples in normal saline were prepared and homogenized with a tissue homogenizer (IKA, Germany) for detecting. According to instructions of ELISA, blank tube, standard tube and measuring tube were all added $0.5 \mathrm{ml}$ digestive juice; then respectively added $0.25 \mathrm{ml}$ of double-distilled water, $0.25 \mathrm{ml}$ standard solution and $0.25 \mathrm{ml}$ test sample. What is following is that $0.5 \mathrm{ml}$ regent I was added and standing for 10 min after mixing; $0.5 \mathrm{ml}$ regent II was added and standing for 5 min after mixing; $1 \mathrm{ml}$ regent III was added and kept in water bath at $60^{\circ} \mathrm{C}$ for $15 \mathrm{~min}$ after mixing. At last, the tubes were cooled in water and centrifuged at $4^{\circ} \mathrm{C}$ for $10 \mathrm{~min}(3500 \mathrm{r} /$ $\mathrm{min}$ ) to obtain supernatants, then absorbance values was measured at $550 \mathrm{~nm}$ and the Hyp content was calculated according to the ELISA kit.

\section{Preparation of mouse peritoneal macrophages}

Each mouse was injected intraperitoneally $4 \%$ thiol-ethyl starch broth $2 \mathrm{ml}$ three days in advance. Then mice were sacrificed and $5 \mathrm{ml}$ PBS was injected intraperitoneally with half an hour massage. After that, cell suspension was extracted and added to the culture medium after it washed and adherent cultured for two hours. What is following is that adherent cells were trypsinized and collected. Then cells were adjusted to concentration of $2 \times 10^{6}$ cells per ml, inoculated to 96 -well plates $(100 \mathrm{uL}$ per well, for detection of TNF- $\alpha$ ) and 24-well plates $(500 \mathrm{uL}$ per well, for neutral red uptake assay) and incubated at $37^{\circ} \mathrm{C}$. Four hours later, the cells were purified by refreshing the medium.

\section{Detection of phagocytosis ability of macrophages}

CS sponge leaching liquor was added to culture medium at the concentrations from 1 to $1000 \mathrm{ug} / \mathrm{mL}$ culture medium. Incubation for 48 hours, the medium was discarded and $1000 \mathrm{uL}$ of $0.07 \%$ neutral red solution was added in each well and cultured for another 1 hour. Then solution was discarded and each well was washed three times with washing liquid and blotted up with filter paper. After that, the lysing solution was added to each well and kept overnight at $4^{\circ} \mathrm{C}$. Finally, the absorbance was recorded at 540 $\mathrm{nm}$ and saline was used for blank test.

\section{Test of TNF- $\alpha$ secretion of macrophages}

When the incubation of macrophages in 96-well plates at $37^{\circ} \mathrm{C}$ for 24 hours finished, the medium was replaced with serum free medium and cultured for another 24 hours in the same conditions. Then medium was substituted by $200 \mathrm{uL}$ serum free medium which containing different concentration of CS sponge leaching liquid (1-1000 ug/mL). After $48 \mathrm{~h}$ incubation, upper medium was obtained and kept at $-80^{\circ} \mathrm{C}$ for ELISA kit detection (antibodies were purchased from R\&D Systems, USA).

\section{Statistical analysis}

The data were expressed as the mean \pm standard deviation (S.D.) and SPSS 17.0 software was used to analyze the data of the test. The means of the different groups were using one-way Kruskal-Wallis test. Significant differences were accepted when P-values were less than 0.05 .

\section{Results}

\section{The basic properties of chitin and sepia ink sponge}

Chitin and sepia ink colloidal can be prepared into different forms of CS sponge as needed, as shown in Figure 1. The deacetylation of CS sponge used in this experiment is $33.5 \%$. 


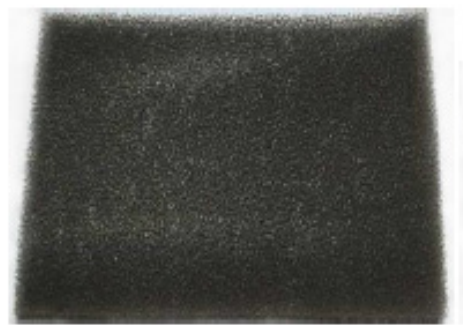

A

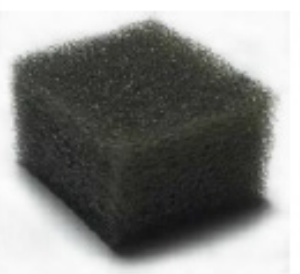

B
FIGURE 1 - A. Sheet of sponge. B. Square sponge.

\section{Deep second degree burn cutaneous wound healing}

As shown in Figure 2, results illustrated the gross determinations of wound healing process. At the beginning, the burn size of each group increased because of edema in all groups. Then the severity was reduced and healing effects occurred after 7 , 14 and day 21. From day 7 to 21 , wound size of CS and SG group was significantly lower than control group $(\mathrm{p}<0.05)$. On day 21 , there was a significant difference between $\mathrm{CS}$ and $\mathrm{SG}(\mathrm{p}<0.05)$.

A

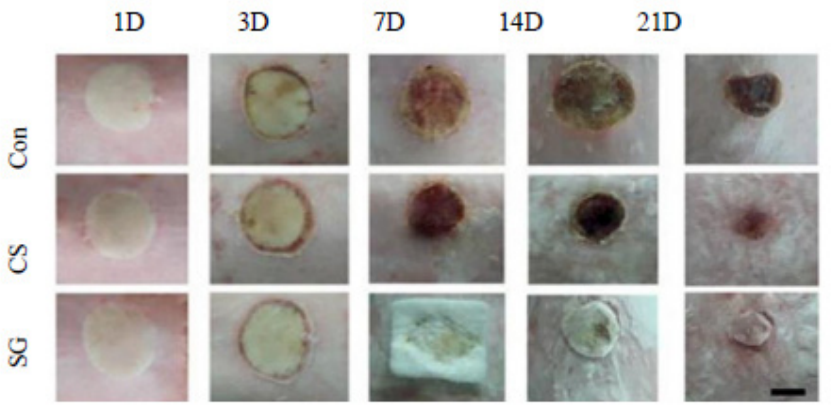

B

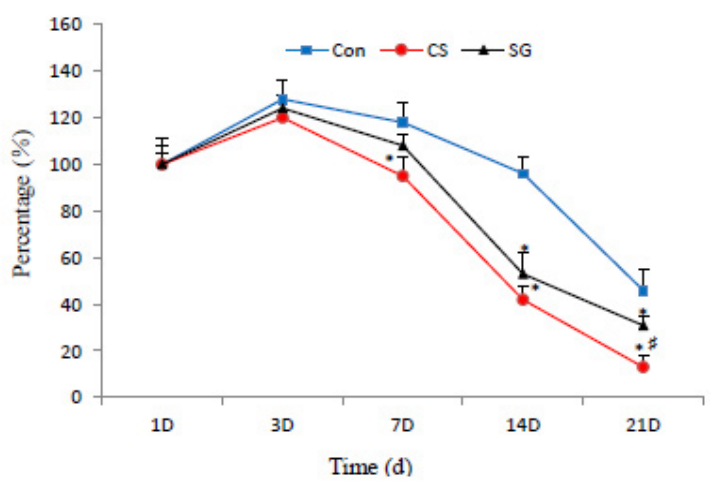

FIGURE 2 - Postburn wound size obtained from injury site. Con as control group; CS as CS sponge; SG as Surgicel Gauze ${ }^{\circledR}$. The scale bar is $0.5 \mathrm{~mm}(\mathbf{A})$. Determination for the percentage of burn healing process by Image J software (B) ${ }^{*} \mathrm{p}<0.05$ vs. Con group; ${ }^{*} \mathrm{p}<0.05$ vs. SG group).

\section{Healing effects of CS sponge on wound site}

Figure 3 showed that TGF- $\beta_{1}$ was significantly enhanced by $\mathrm{CS}$ and SG on day 3and $7(\mathrm{p}<0.05)$. In CS group, it nearly reduced to normal level on day 21 . On day 14 and day 21 , there was a significant difference between $\mathrm{CS}$ and $\mathrm{SG}$ group $(\mathrm{p}<0.05)$.

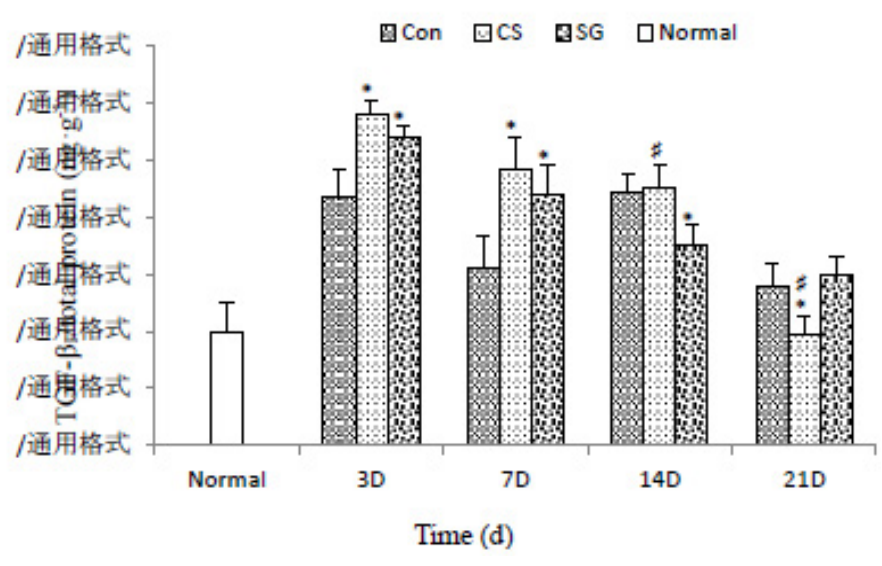

FIGURE 3 - Contents of TGF- $\beta_{1}$ in the wound site. Results are expressed as mean $\pm \mathrm{SD}(\mathrm{n}=3)$. $\left({ }^{*} \mathrm{p}<0.05\right.$ vs. Con group; ${ }^{*} \mathrm{p}<0.05$ vs. SG group $)$.

Figure 4 illustrated that IL-6 was significantly elevated both in CS and SG group from three to 14 days $(\mathrm{p}<0.05)$, then it declined to normal level earlier compared to control group.

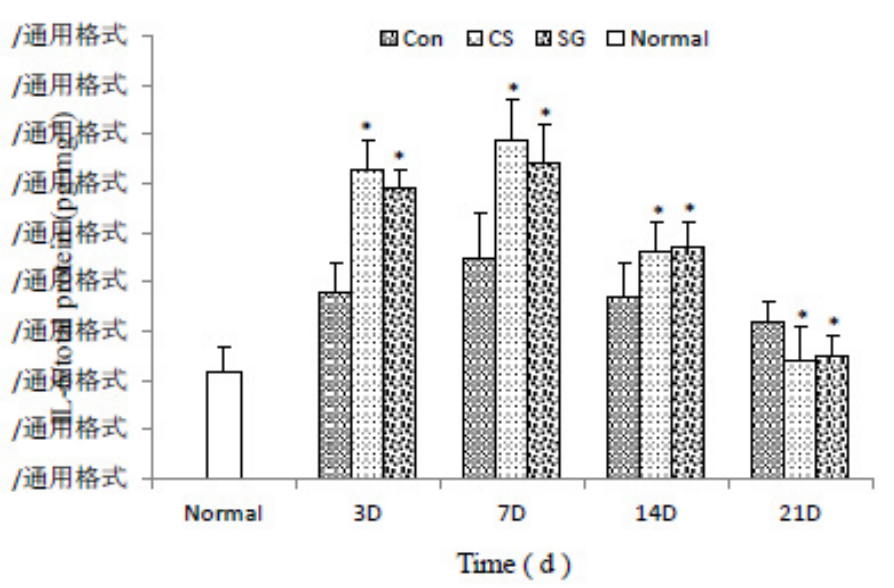

FIGURE4 - Contents of IL-6 in the wound site. Results are expressed as mean $\pm \mathrm{SD}(\mathrm{n}=3) .\left({ }^{*} \mathrm{p}<0.05 v s\right.$. Con group).

Figure 5 depicted that MMP-1was significantly increased by $\mathrm{CS}$ and SG on day 3 and $7(\mathrm{p}<0.05)$. In CS group, it reached its peak value on day 14 , and there was a significant difference compared to SG and control group $(\mathrm{p}<0.05)$. 


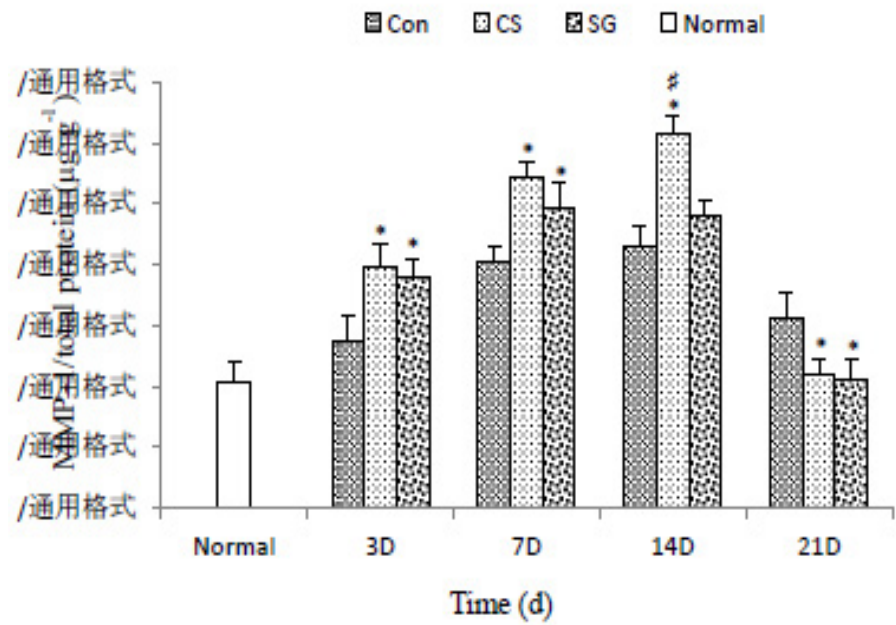

FIGURE 5 - Contents of MMP-1 in wound site. Results are expressed as mean $\pm \mathrm{SD}(\mathrm{n}=3) .\left({ }^{*} \mathrm{p}<0.05 v s\right.$. Con group; ${ }^{*} \mathrm{p}<0.05 v s . \mathrm{SG}$ group $)$.

Figure 6 suggested that Hyp was significantly stimulated by CS and SG from 3 to $21 \mathrm{~d}(\mathrm{p}<0.05)$. On day 14 , there was a significant difference between CS and SG group $(\mathrm{p}<0.05)$.

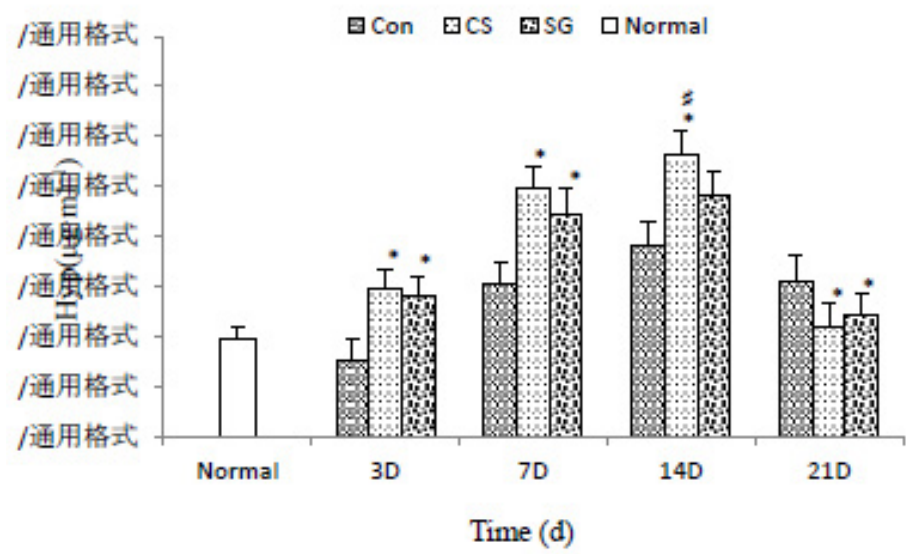

FIGURE 6 - Contents of Hyp in wound site. Results are expressed as mean $\pm \mathrm{SD}(\mathrm{n}=3) .\left({ }^{*} \mathrm{p}<0.05 v s\right.$. Con group; ${ }^{*} \mathrm{p}<0.05 v s . \mathrm{SG}$ group).

\section{Effects of CS sponge on macrophages in vitro}

Figure 7 revealed the phagocytosis ability of macrophages was significantly enhanced with the concentration by CS leaching liquid increasing $(\mathrm{p}<0.05)$.

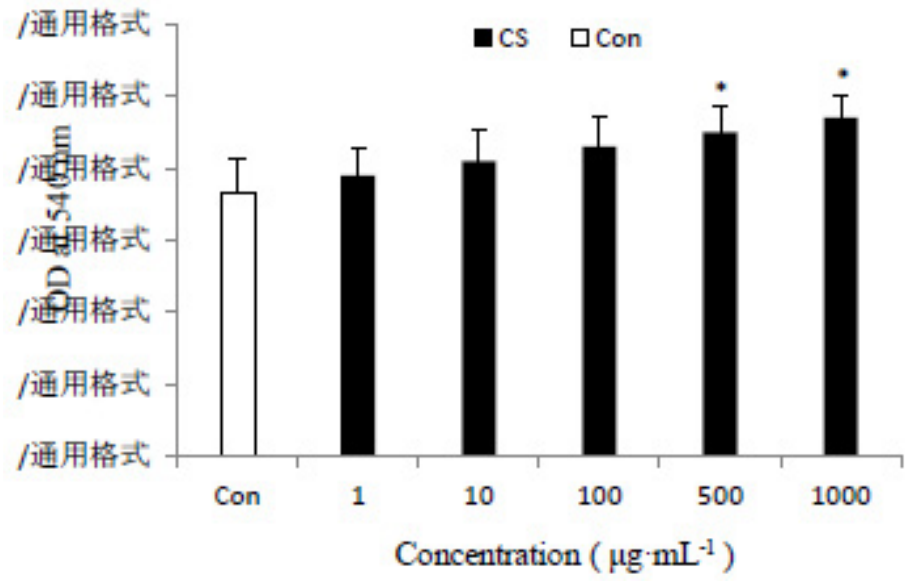

FIGURE7 - Phagocytosis ability of macrophages influenced by CS at different concentrations. Results are expressed as mean \pm SD $(n=3)$. $\left({ }^{*} \mathrm{p}<0.05 v s\right.$. Con group).

Figure 8 described TNF- $\alpha$ production of macrophages at each testing concentration was significantly promoted by $\mathrm{CS}$ at concentrations of 100,500 and $1000 \mu \mathrm{g} \cdot \mathrm{mL}^{-1}(\mathrm{p}<0.05)$.

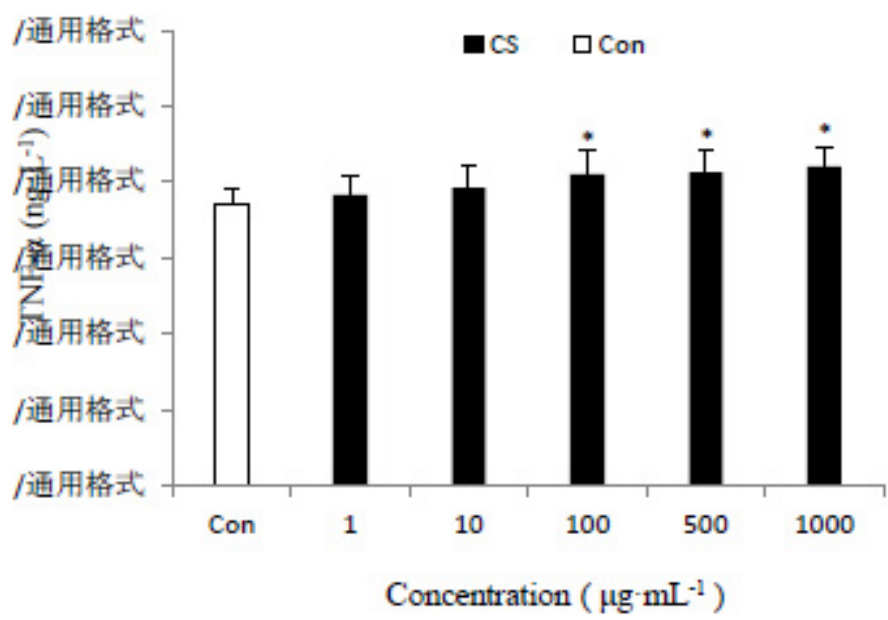

FIGURE 8 - TNF- $\alpha$ secretion of macrophages influenced by CS at different concentrations. Results are expressed as mean \pm SD $(n=3)$. $\left({ }^{*} \mathrm{p}<0.05 v s\right.$. Con group).

\section{Discussion}

TGF- $\beta_{1}$ and IL- 6 are two important kinds of cytokines in wound remodeling. Many authors have investigated the changes of TGF- $\beta_{1}$ and IL- 6 during the wound healing. Gopal et al. ${ }^{11}$ examined chitosan-based copper nanocomposite (CCNC) in rat wound healing and discovered TGF- $\beta_{1}$ was significantly increased in the CCNC-treated rats. Studies also 
showed that exogenous TGF- $\beta_{1}$ applied in the wound area can significantly promote various types of wound repair. Li et $a l .{ }^{12}$ found that chitosan membrane containing TGF- $\beta_{1}$ promoted the proliferation of osontoblast-like cells than that without TGF. Gallucci et al. ${ }^{13}$ found that granulation tissue formation was impaired in IL- 6 gene knock-out rats and these animals had longer healing time than wild type control.

In the present study, results showed TGF- $\beta_{1}$ and IL-6 had the similar change trend compared to the results above, the contents of which were increased in some level at the early period of wound healing. TGF- $\beta_{1}$ and IL- 6 in the CS and SG group were all significantly $(\mathrm{p}<0.05)$ enhanced from day 3 , and then both of them gradually declined to normal levels. But CS sponge showed the better moderating effect, which made the content of TGF- $\beta_{1}$ and IL- 6 fast reach a higher level and drop to a normal standard earlier compared to control group and SG group. Hence, it can be seen that CS sponge has more obviously regulating effect on the cytokines of TGF- $\beta 1$ and IL- 6 during the wound healing process.

Under normal conditions, collagenase, or MMP-1, is restricted to a few tissues which show intense remolding ${ }^{14}$. Collagen degradation is mainly regulated by collagenase. Hyp is a unique amino acid, which occupies the constant ratio in collagen fibers. Usually collagen synthesis is reflected by measuring the amount of $\mathrm{Hyp}^{15}$. Shin et al. ${ }^{16}$ assessed the role of MMP-1 in collagen remodeling during wound healing, and inferred that increased MMP-1 enabled remodeling the extracellular matrix. Sun et al. ${ }^{17}$ also examined the MMP-1 production fluctuations in the experiment of Galla chinensis (GAC) extracts applying on UVB-irradiated in hairless mice, but the results showed that GAC may suppress MMP-1 expression, by which can form a more smooth and elastic skin tissue.

Compared to the researches above, our present experiment found both MMP-1 and Hyp were significantly $(\mathrm{p}<0.05)$ increased in CS group and SG group and quickly reduced to normal levels, the adjustment effect was particularly obvious in CS group. It is speculated that CS sponge may have a different regulatory mechanism, through which can accelerate decomposition and regulation of the wound collagen by MMP-1 and Hyp, to achieve better healing effect.

TNF- $\alpha$ is mainly produced by activated macrophages, the content of

which is considered as an indicator to measure the activity of macrophages ${ }^{18}$. Hübner et al. ${ }^{19}$ found a strong and early induction of TNF- $\alpha$ after cutaneous injury in vivo of mice and highest level of TNF- $\alpha$ was seen at 12-14 h after wounding. In our present research, it also showed that CS sponge promoted the activity of macrophage which was reflected by the content of TNF- $\alpha$. But our experiment was conducted in vitro, the effect of CS sponge for TNF- $\alpha$ in vivo still need to be explored.

Present studies show that CS sponge is a relative safe and effective biomaterial, but there are still some limitations in this study. For clinical application, the sample sizes of the experimental animals are small, and the data is primary. Also, different species of animals should be applied to achieve more convincing and comprehensive results. Therefore, further investigation should be conducted and the relevant results would be reported in our following work.

\section{Conclusions}

CS sponge can effectively promote wound healing by activating macrophages and exerting significant effects on secretion of kinds of cytokines, such as TGF- $\beta_{1}$, IL-6, MMP-1, Hyp and TNF- $\alpha$. Present study only conducted basic research of CS sponge, further investigations should be performed in future.

\section{References}

1. Azuma K, Nishihara M, Shimizu H, Itoh Y, Takashima O, Osaki T, Itoh N, Imagawa T, Murahata Y, Tsuka T, Izawa H, Ifuku S, Minami S, Saimoto H, Okamoto Y, Morimoto M. Biological adhesive based on carboxymethyl chitin derivatives and chitin nanofibers. Biomaterials. 2015 Feb;42:20-9. PMID: 25542790.

2. Jayakumar R, Prabaharan M, Kumar SPT, Nair SV, Tamura H. Biomaterials based on chitin and chitosan in wound dressing application. Biotechnol Adv. 2011 May-Jun;29(3):322-37. PMID: 21262336.

3. Lee CG. Chitin, chitinases, and chitinase-like proteins in allergic inflammation and tissue remodeling. Yonsei Med J. 2009 Feb;50(1):22-30. PMID: 19259344.

4. Zong AZ, Zhao T, Zhang Y, Song XL, Shi YK, Cao HZ, Liu $\mathrm{CH}$, Cheng YN, Qu XJ, Cao JC, Wang FS. Anti-metastatic and anti-angiogenic activities of sulfated polysaccharide of Sepiella maindroni ink. Carbohyd Polym. 2013 Jan;91(1):403-9. PMID: 23044150.

5. Takaya Y. Biological activities of natural resources around us are now in the limelight. Yakugaku Zasshi. 2000 Nov;120(11):1075-89. PMID: 11190195.

6. Chen SG, Wang JF, Xue CH, Li H, Sun BB, Xue Y, Chai WG. Sulfation of a squid ink polysaccharide and its inhibitory effect on tumor cell metastasis. Carbohyd Polym. 2010 Jul;81(3):560-6. doi: 10.1016/j.carbpol.2010.03.009.

7. Broekema FI, van Oeveren W, Selten MH, Meijer RJ, de Wolf JT, Bos RR. In vivo hemostatic efficacy of polyurethane foam compared to collagen and gelatin. Clin Oral Investig. 2013 May;17(4):1273-8. PMID: 22855267.

8. Otani Y, Tabata Y, Ikada Y. A new biological glue from gelatin and 
poly (L-glutamic acid). J Biomed Mater Res. 1996 Jun;31(2):15866. PMID: 8731204.

9. Zhang W, Sun YL, Chen DH. Effects of chitin and sepia ink hybrid hemostatic sponge on the blood parameters of mice. Mar Drugs. 2014 Apr;12(4):2269-81. PMID: 24727395.

10. Fan ZW, Pang YX, Wang K, Yu FL, Wang D, Yang Q, Ma QS, Li XT, Zou J, Zhang WQ, Wu LF. Blumea balsamifera oil for the acceleration of healing of burn injuries. Molecules. 2015 Sep 17;20(9):17166-79. PMID: 26393555.

11. Gopal A, Kant V, Gopalakrishnan A, Tandan SK, Kumar D. Chitosan-based copper nanocomposite accelerates healing in excision wound model in rats. Eur J Pharmacol. 2014 May;731:819. PMID: 24632085.

12. Li F, Liu X, Zhao S, Wu H, Xu HH. Porous chitosan bilayer membrane containing TGF- $\beta_{1}$ loaded microspheres for pulp capping and reparative dentin formation in a dog model. Dent Mater. 2013 Dec;30(2):172-81. PMID: 24332410.

13. Gallucci RM, Simeonova PP, Matheson JM, Kommineni C, Guriel JL, Sugawara T, Luster MI. Impaired cutaneous wound healing in interleukin-6-deficient and immunosuppressed mice. Faseb J. 2000 Dec;14(15):2525-31. PMID: 11099471.

14. Sachlos E, Czernuszka JT. Making tissue engineering scaffolds work. Review: the application of solid freeform fabrication technology to the production of tissue engineering scaffolds. Eur Cells Mater. 2003 Jun;5:29-40. PMID: 14562270.

15. Zheng Z, Zhang W, Sun W, Li X, Duan J, Cui J, Feng Z, Mansour HM. Influence of the carboxymethyl chitosan anti-adhesion solutionon the TGF- $\beta_{1}$ in a postoperative peritoneal adhesion rat. J Mater Sci: Mater Med. 2013 Nov;24(11):2549-59. PMID: 23820936.

16. Shin MK, Lee JW, Kim YI, Kim YO, Seok H, Kim NI. The effects of platelet-rich clot releasate on the expression of MMP-1 and type I collagen in human adult dermal fibroblasts: PRP is a stronger MMP1 stimulator. Mol Biol Rep. 2014 Jan;41(1):3-8. PMID: 24293148.

17. Sun ZW, Hwang E, Lee HJ, Lee TY, Song HG, Park SY, Shin HS, Lee DG, Yi TH. Effects of Galla chinensis extracts on UVBirradiated MMP-1 production in hairless mice. J Nat Med. 2015 Jan;69(1):22-34. PMID: 25227288.

18. Yu SF, Koerner TJ, Adams DO. Gene regulation in macrophage activation: differential regulation of genes encoding for tumor necrosis factor, interleukin-1, JE, and $\mathrm{KC}$ by interferon-gamma and lipopolysaccharide. J Leukoc Biol. 1990 Nov;48(5):412-9. PMID: 2121882.

19. Hübner G, Brauchle M, Smola H, Madlener M, Fässler R, Werner S. Differential regulation of pro-inflammatory cytokines during wound healing in normal and glucocorticoid-treated mice. Cytokine. 1996 Jul;8(7):548-56. PMID: 8891436.

\section{Acknowledgements}

The Science \& Technology Plan in Lingnan Normal University (QL1306,ZL1313), project of Scientific and Technological Cooperation and Exchange Program in Guangxi Province (1346011-25), project of Science Technology in Guangdong province (2013B090500036), project of Zhanjiang seafood ingredients sustainable utilization and conservation technology service platform (2014B040404071), Beibu Gulf Rim Biological Resources Development and Utilization Technology Innovation Center, special project of central financial to support the development for local colleges(0003015119), project of Science \& Technology in Zhanjiang city (2013A202-4, 2013A05004).

\section{Correspondence:}

Daohai Chen

Lingnan Normal University

Round Beibu Gulf Institute for the Protection and Utilization of Marine Animals in Medicine

Cunjin Road, 29

Zhanjiang, China

Phone: +86-759-3183819

Fax: 86-759-3183271

dhchen11@21cn.com

Received: Oct 6, 2015

Review: Dec 12, 2015

Accepted: Jan 13, 2016

Conflict of interest: none

Financial source: Spark Program of State Ministry of Science \& Technology (2014GA780071, 2013GA780080)

${ }^{1}$ Research performed at Round Beibu Gulf Institute for the Protection and Utilization of Marine Animals in Medicine, Lingnan Normal University, China. 